\title{
Photoprotection in heteromorphic leaves of savin juniper (Juniperus sabina L.)
}

\author{
J.L. ZHANG ${ }^{*, * *}$, X.H. XU*, X.G. LI*, Y.L. LI", , R.D. GUY*,+, and H.P. CHEN* \\ College of Forestry, Agricultural University of Hebei, 071000 Baoding, China* \\ Department of Forest and Conservation Sciences, Faculty of Forestry, University of British Columbia, \\ V6T 1 Z4 Vancouver, Canada**
}

\begin{abstract}
Savin juniper has green, photosynthetic branchlets with scale and/or needle leaves and these heteromorphic forms may contribute differentially to its success in open, arid environments. To test differences in photoprotection between fully sun-exposed scale-holding branchlets (SHB) and needle-holding branchlets (NHB), we measured gas exchange, chlorophyll (Chl) fluorescence, and pigment concentrations. NHB had higher net photosynthetic rate, stomatal conductance, and intrinsic water-use efficiency. In contrast, SHB had higher nonphotochemical quenching. Chl $a$, Chl $b$, and antheraxanthin concentrations were higher in NHB. SHB had higher zeaxanthin, lutein, and carotenoids (Car), and higher Chl $a / b$, $\mathrm{Car} / \mathrm{Chl}$, and $\alpha$-carotene/ $\beta$-carotene ratios. The results indicate greater engagement of xanthophyll-based thermal dissipation in SHB. Branchlet types acclimate to strong light using different strategies; SHB by investing in photoprotective mechanisms, and NHB by having a high photosynthetic capacity. Heterophylly may allow savin juniper to be more functionally flexible under variable environmental conditions.
\end{abstract}

Additional key words: gas exchange; leaf morphology; photoinhibition; Sabina vulgaris Ant.; water-use efficiency.

\section{Introduction}

Many plant species alter their leaf morphology with age or environment, and this phenomenon is termed heterophylly (Nakayama et al. 2017). Heteroblasty is a kind of heterophylly whereby leaf formed at a young age differs from the form produced at a more mature age (Nicotra et al. 2011). Heterophylly and heteroblasty have evolved multiple times during plant evolution in different unrelated taxa (Nakayama et al. 2017). Since leaf morphology significantly influences the physiological and ecological functions of a plant, heterophylly may play an important role in acclimation to the environment (Winn 1999, Hao et al. 2017). Leaf architecture influences such critical processes as anatomical structure, hydraulic properties, energy budgets, and gas exchange, and heterophylly is an adaptation that allows individuals to maximize their photosynthetic performance in the face of environmental variation (Winn 1999). In heterogeneous environments, plants capable of plastic modifications of leaf size and shape are expected to have better fitness compared to other plants (Palacio-López et al. 2015). For example, the desert tree Populus euphratica Oliv. has lanceolate, broad-ovate, and dentate broad-ovate leaves distributed in different layers of the canopy. Compared to the other leaf types, the dentate broad-ovate leaves have more obvious xeromorphic characteristics and higher photosynthesis under drought, and can efficiently adapt to changing conditions (Hao et al. 2017).

The most dramatic instances of heterophylly occur in species where individuals occupy sharply contrasting environments. For example, many emergent aquatic plants produce distinctly different submerged vs. aerial leaves (Kane and Albert 1982, Deschamp and Cooke 1985) and some tropical vines produce different leaves for full sun and deep shade (Ray 1987, 1990; Lee and Richards 1991). The functional differences between submerged and emergent leaves, or between sun and shade leaves, are relatively

Received 17 February 2019, accepted 20 May 2019.

${ }^{+}$Corresponding author; phone: 86-031-2752-8758, fax: 86-031-2752-8799, e-mail: liyuling0425@126.com; phone: 1-604-822-6023, fax: 1-604-822-9133, e-mail: rob.guy@ubc.ca

Abbreviations: A - absorbance; $\mathrm{Chl}$ - chlorophyll; $C_{\mathrm{i}} / C_{\mathrm{a}}$ - ratio of intercellular to atmospheric $\mathrm{CO}_{2}$ concentration; $E$ - transpiration rate; ETR - electron transport rate; $\mathrm{F}_{0}$ - minimal fluorescence yield of the dark-adapted state; $\mathrm{F}_{\mathrm{m}}$ - maximal fluorescence yield of the darkadapted state; $\mathrm{F}_{\mathrm{m}}{ }^{\prime}$ - maximal fluorescence yield of the light-adapted state; $\mathrm{F}_{\mathrm{s}}$ - steady-state fluorescence yield; $\mathrm{F}_{\mathrm{v}} / \mathrm{F}_{\mathrm{m}}-\mathrm{PSII}$ maximal efficiency in the dark state; $g_{\mathrm{s}}-$ stomatal conductance; NHB - needle-holding branchlets; NPQ - nonphotochemical quenching; $P_{\mathrm{N}}-$ net photosynthetic rate; $P_{\mathrm{N}} / C_{\mathrm{i}}$ - instantaneous efficiency of carboxylation; $\mathrm{SHB}$ - scale-holding branchlets; $\mathrm{WUE}_{\mathrm{i}}-$ intrinsic water-use efficiency; $\Phi_{\mathrm{PSII}}-\mathrm{PSII}$ operational efficiency.

Acknowledgements: We thank Dr Aihua Yan, Dr Kejiu Du, and Dr Jizhong Xu for lab assistance; Dr Bingxiang Liu and Dr Hongbo Cao for chromatography assistance; and Feng Mu, Xin Lin, An'ning Wang, and Gechang Liu for experiment assistance. This research was supported by the Natural Science Foundation of Hebei Province (C2011204096), the State Forestry Administration '948' Project (2009-4-29), the Doctoral Student Innovation Capability Promotion Project of Hebei Agricultural University, and the Key Laboratory of Forest Tree Germplasm Resources and Forest Conservation of Hebei Province. 
obvious, but in other cases, such as in heteroblastic leaf development, the functional differences between different leaf forms are not so clear. Heteroblastic leaf development may be gradual or abrupt. Many woody plants show very distinct changes in their leaf form from a 'juvenile' phase to a 'mature' phase. For example, the juvenile leaves of Eucalyptus globulus Labill. are oval and sessile, while mature-form leaves are slender lanceolate or sickle-shaped and petiolate. Although age-related, this transition from producing juvenile to mature leaves can also depend on the environment (Steinbauer 2002).

Many members of the Cupressaceae have distinctly different juvenile and adult foliage. For example, the evergreen shrub-tree species savin juniper (Juniperus sabina L., syn. Sabina vulgaris Ant.) has green, photosynthetic branchlets with either needle-like juvenile leaves and/or scale-like adult leaves. Adult plants growing in the open have both scale-holding branchlets (SHB) and needleholding branchlets (NHB), whereas most seedlings established under a tree canopy have only NHB (He and Zhang 2001, Tanaka-Oda et al. 2010). Previous research has shown that scale leaves of savin juniper were better adapted to sunny environments due to their higher tolerance to photoinhibition and higher water-use efficiency, whereas needle leaves were more appropriate to the shade with their lower dark respiration rate and, hence, lower lightcompensation point (He and Zhang 2001, Tanaka-Oda et al. 2010).

Savin juniper is native to parts of southern Europe and central and eastern Asia. In China, it is mainly distributed in arid and semi-arid areas of the north and northwest $\left(36-49^{\circ} \mathrm{N}, 86-116^{\circ} \mathrm{E}\right)$ (Wang et al. 2014). It is the dominant and only evergreen shrub in the Mu Us Desert of Inner Mongolia (He and Zhang 2003, He et al. 2003). Savin juniper is propagated from cuttings for ornamental purposes and to combat desertification. It can endure strong light, high temperature, wind erosion, and sand burial, so is an excellent species for impeding wind, fixing sand, and conserving soil and water in arid and semi-arid areas (Kang et al. 2003).

Light energy absorbed by photosynthetic antenna pigments powers carbon fixation, but if present in excess, it may also cause photoinhibition or lead to photooxidative stress (Niyogi et al. 1997, Zhang et al. 2017). Although strong light is the direct cause of photoinhibition, drought and low or high temperature stress can promote it indirectly (Xu 2003). Photon flux density, plant age, and leaf condition determine whether or not photoinhibition would occur, as indicated by a depression of net photosynthetic rate $\left(P_{\mathrm{N}}\right)$ and PSII maximal efficiency in the dark state $\left(\mathrm{F}_{\mathrm{v}} / \mathrm{F}_{\mathrm{m}}\right)$ (Kitao et al. 2000, Ribeiro et al. 2009). Plants have a variety of mechanisms to avoid photooxidation by either reducing light absorption (including anthocyanin or rhodoxanthin accumulation, photophobic motion of leaves or chloroplasts, etc.), scavenging reactive oxygen species or invoking alternative means of dissipating light energy (e.g., by photorespiration, or as heat by xanthophyll and carotenes cycle) (Weger et al. 1993, Pastenes et al. 2005, Cazzaniga et al. 2016).

Considerable research has shown that higher carotenoid
(Car) concentrations, including carotenes and xanthophylls, are associated with stronger photoprotection (DemmigAdams and Adams 1996, Lee and Schmidt-Dannert 2002, Ke 2003, Ueno et al. 2016, Kopsell et al. 2017, Yuan et al. 2017, Zakar et al. 2017). The principal carotenes are the mutual isomers $\alpha$-carotene and $\beta$-carotene. The xanthophylls, mainly including violaxanthin, antheraxanthin, zeaxanthin, and lutein, are derived from carotenes and constitute the most varied pigments in chloroplasts (Demmig-Adams and Adams 1996, Niyogi et al. 1997, $\mathrm{Ke}$ 2003). Under high light conditions, violaxanthin is reversibly deepoxidated to antheraxanthin and then zeaxanthin in a process known as the xanthophyll cycle (Demmig-Adams and Adams 1996, Kopsell et al. 2017). Zeaxanthin plays a key role in the process of energy dissipation, and may do so by directly quenching the excited state chlorophyll (Chl) (Demmig-Adams and Adams 1996). Excited Chl may also be quenched by lutein located within the light-harvesting complex of PSII (Jahns and Holzwarth 2012).

Previous work indicates that the needle leaves of savin juniper are more effective at maximizing photosynthetic production under light-limited conditions, while the scale leaves are better able to avoid photoinhibition (TanakaOda et al. 2010) and are more resistant to drought and high light stress (Zhang et al. 2017, 2018). However, the involvement of Car pigments of scale vs. needle leaves, and how their concentrations or ratios vary is unknown. Furthermore, the fact that both leaf forms do occur on adult plants at fully sun-exposed positions suggests that scale and needle leaves are both able to adjust to strong light but may do so using different strategies. We hypothesized that branchlets with scale leaves have stronger photoprotection than those with needle leaves, but may have lower photosynthetic capacity. To test this hypothesis, we measured gas-exchange parameters, Chl fluorescence parameters, and pigment concentrations and ratios in fully sun-exposed leaves of both forms.

\section{Materials and methods}

Study site and climate data: This study utilized mature ( $>7$ years), essentially untended landscape plantings of savin juniper clones at the Hebei Agricultural University $\left(38^{\circ} 49^{\prime} 23^{\prime \prime} \mathrm{N}, 115^{\circ} 26^{\prime} 40^{\prime \prime} \mathrm{E}, 21.4 \mathrm{~m}\right.$ a.s.1.), Baoding, China. These plantings were monospecific, with no cover and little or no herbaceous cover underneath. Coverage by savin juniper was more than $90 \%$. There were more than 500 individuals at the study site. Based on a random sampling of 45 plants, the stem diameter at ground level was $3.01 \pm 0.58 \mathrm{~cm}($ mean $\pm \mathrm{SD})$, the height was $116.0 \pm 11.6 \mathrm{~cm}$, crown breadth from east to west was $161.1 \pm 32.1 \mathrm{~cm}$, and crown breadth from north to south was $166.9 \pm 33.7 \mathrm{~cm}$. The proportion of foliage as viewed vertically from the side (Fig. 1) that consisted of branchlets with scale leaves was estimated to be $79 \pm 2 \%$ and that of branchlets with needle leaves was $21 \pm 2 \%$. The study site is characterized by a continental monsoon climate with four distinct seasons, dry and windy spring, hot and rainy summer, cool autumn, and a cold and relatively dry winter. Mean annual tempera- 


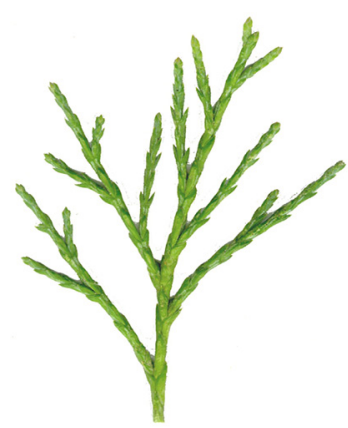

Scale leaves

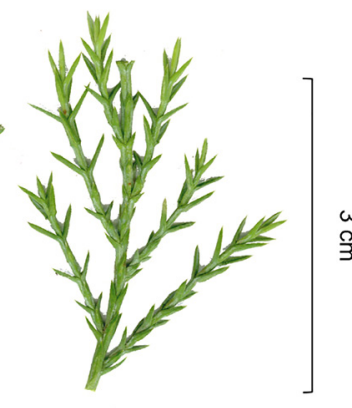

Needle leaves
Fig. 1. Branchlets with scale and needle leaves of Juniperus sabina $\mathrm{L}$.

ture from $2006-2016$ was $13.7^{\circ} \mathrm{C}$ and the mean annual precipitation was $513.5 \mathrm{~mm}$ (Wang et al. 2017). The precipitation is concentrated from June to August, and the period of active growth in J. sabina is from April throughout October. The soil is cinnamon soil (Zhang et al. 2014) and the soil moisture content at the time of the experiment was $25.9-28.4 \%$.

Gas exchange and $\mathrm{Chl}$ fluorescence: Measurement of gas-exchange parameters was conducted between 11:00 and 15:00 h on a clear day (19 July 2017). Current-year SHB and NHB from the sun-exposed, upper, outer, and south-facing canopy were measured using a $L I-6400 X T$ portable photosynthesis system using ambient light and a $2 \times 3 \mathrm{~cm}^{2}$ leaf chamber ( $\mathrm{Li}$-Cor, Lincoln, NE, USA). The foliage was arranged to completely fill the chamber window with as little branch overlap as possible. Measurements of branchlet $P_{\mathrm{N}}$, transpiration rate $(E)$, stomatal conductance $\left(g_{\mathrm{s}}\right)$, and the ratio of intercellular to atmospheric $\mathrm{CO}_{2}$ concentration $\left(C_{\mathrm{i}} / C_{\mathrm{a}}\right)$ were taken. The intrinsic water-use efficiency $\left(\mathrm{WUE}_{\mathrm{i}}\right)$ and the instantaneous efficiency of carboxylation were calculated as $P_{\mathrm{N}} / g_{\mathrm{s}}$ and $P_{\mathrm{N}} / C_{\mathrm{i}}$ (Zhang et al. 2001), respectively. Air temperature averaged $38.1^{\circ} \mathrm{C}$, and the relative humidity was approximately $50 \%$. The mean leaf-to-air vapor pressure deficit was $1.91 \mathrm{kPa} . \mathrm{CO}_{2}$ concentration was about $400 \mu \mathrm{mol} \mathrm{mol}^{-1}$. Photosynthetically active radiation was between 1,100 $1,200 \mu \mathrm{mol}\left(\right.$ photon) $\mathrm{m}^{-2} \mathrm{~s}^{-1}$ and the air flow rate into the cuvette was $500 \mu \mathrm{mol} \mathrm{s}{ }^{-1}$.

Chl fluorescence was evaluated concurrently, on the same or adjacent branchlets, with a modulated fluorometer (FMS2, Hansatech, King's Lynn, UK). Measurements of the foliage minimal fluorescence yield $\left(\mathrm{F}_{0}\right)$ and the maximal fluorescence yield $\left(\mathrm{F}_{\mathrm{m}}\right)$ of the dark-adapted state (30 min) were taken. Then, after $30 \mathrm{~min}$ of light exposure, we measured the steady-state fluorescence yield $\left(F_{s}\right)$ and the maximal fluorescence yield of the light-adapted leaves $\left(F_{m}{ }^{\prime}\right)$. PSII maximal efficiency in the dark state $\left(\mathrm{F}_{\mathrm{v}} / \mathrm{F}_{\mathrm{m}}\right)$, PSII operational efficiency $\left(\Phi_{\mathrm{PSII}}\right)$, electron transport rate (ETR), and nonphotochemical quenching (NPQ) were calculated as $\left(\mathrm{F}_{\mathrm{m}}-\mathrm{F}_{0}\right) / \mathrm{F}_{\mathrm{m}},\left(\mathrm{F}_{\mathrm{m}}{ }^{\prime}-\mathrm{F}_{\mathrm{s}}\right) / \mathrm{F}_{\mathrm{m}}{ }^{\prime}$, PAR $\times 0.5 \times \Phi_{\text {PSII }} \times 0.84$, and $\left(F_{m}-F_{m}{ }^{\prime}\right) / F_{m}{ }^{\prime}$, respectively (Mouget and Tremblin 2002).
Pigments: For pigment analysis, branchlets were sampled immediately after fluorescence measurements and frozen in liquid nitrogen $\left(-80^{\circ} \mathrm{C}\right)$ for transport back to the laboratory. Foliage samples of $0.1 \mathrm{~g}$ were thoroughly homogenized in $2 \mathrm{~mL}$ of $95 \%$ ethanol in a $10-\mathrm{mL}$ centrifuge tube with a high speed dispersion homogenizer (FJ200-SH, Shanghai, China). Another $8 \mathrm{~mL}$ of $95 \%$ ethanol was added to the tube for centrifugation at $11,270 \times g$ at $4^{\circ} \mathrm{C}$ for $5 \mathrm{~min}$ (Anke, T.G.L-16-aR). The absorbance (A) of the supernatant was measured with a spectrophotometer (TU-1901, Beijing Purkinje General Instrument Co. Ltd., Beijing, China) at 649, 664, and $470 \mathrm{~nm}$. Concentrations of Chl $a$, Chl $b$, and their sum, and total Car were expressed in $\mathrm{mg} \mathrm{g}^{-1}$ and calculated using the following equations (Lichtenthaler 1987):

Chl $a=13.36 \times \mathrm{A}_{664}-5.19 \times \mathrm{A}_{649}$

Chl $b=27.43 \times \mathrm{A}_{649}-8.12 \times \mathrm{A}_{664}$

Car $=\left(1000 \times \mathrm{A}_{470}-2.13 \times \mathrm{Chl} a-97.64 \times \mathrm{Chl} b\right) / 209$

Individual Car concentrations were measured by high performance liquid chromatography using methods modified from Cao et al. (2012), Liu et al. (2007), and Paine et al. (2005). For this purpose, $200 \mathrm{mg}$ of foliage were milled to powder in a $10-\mathrm{mL}$ centrifuge tube using a liquid nitrogen grinder. Then, $2 \mathrm{~mL}$ of pigment extracting solution (hexane:acetone:ethanol, $2: 1: 1$, containing $0.01 \%$ butylated hydroxytoluene) was added and pigments were extracted at $4^{\circ} \mathrm{C}$ for $10 \mathrm{~min}$ by using ultrasound (SCIENTZ, $S B-3200 D T D N)$ and then centrifuged at $11,270 \times g$ at $4^{\circ} \mathrm{C}$ for $5 \mathrm{~min}$ (Anke, T.G.L-16-aR). The pellet, if not blanched, was resuspended and ultrasound and centrifugation were repeated. A $500-\mu \mathrm{L}$ aliquot of supernatant was transferred to a new 2-mL centrifuge tube, followed by addition of $1 \mathrm{~mL}$ of $10 \% \mathrm{KOH}-$ methanol solution. After $12 \mathrm{~h}, 500 \mu \mathrm{L}$ of $1 \% \mathrm{NaCl}$ in water was added, and tubes were centrifuged at $13,685 \times g$ at $4^{\circ} \mathrm{C}$ for 5 min (Thermo, Fresco 17). A $400-\mu \mathrm{L}$ aliquot of the supernatant was transferred to another 2-mL centrifuge tube and dried on a centrifugal evaporator (EYELA, Japan). The residue was dissolved in $500 \mu \mathrm{L}$ of methyl tert-butyl ether and the solution filtered through organic microporous membrane $(0.22 \mu \mathrm{m})$ and injected into a 2-mL brown chromatography sample bottle lined with a $250-\mu \mathrm{L}$ glass insert.

Car pigments were separated on a C30 (Devolosil, Nomura Chemical Co. Ltd.) chromatographic column with a Waters 1525 high performance liquid chromatograph equipped with a 2707 automatic sampler, a 2998 two level array detector, and Empower chromatogram management software. The detection wavelength was $450 \mathrm{~nm}$. The

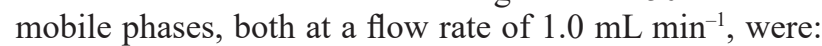
A) methanol:acetonitrile, $1: 3$, containing $0.01 \%$ butylated hydroxytoluene and $0.05 \%$ triethylamine; and B) methyl tert-butyl ether containing $0.01 \%$ butylated hydroxytoluene. Authentic antheraxanthin, zeaxanthin, lutein, $\alpha$-carotene, and $\beta$-carotene were purchased from CaroteNature (Lupsingen, Switzerland).

Leaf mass area: Because scale leaves are more succulent than needle leaves (Fig. 1), we estimated fresh mass over dry mass ratios and 'leaf' mass per unit area of the different 
branchlet types to check whether patterns would change if results were expressed on a different basis. Branchlet fresh mass was measured and then area was determined using an image scanner (EPSON Expression 10000XL) and image processing software (Adobe Photoshop CC 2017). Branchlets were then oven-dried $\left(60^{\circ} \mathrm{C}, 72 \mathrm{~h}\right)$ to a constant mass and weighed again $(n=25)$.

Data analysis: Complete data sets were compiled for 39 samples from each foliage type. Most statistical comparisons were performed by two-sample $t$-tests in SigmaPlot 12.0. To meet assumptions of normality and homogeneity of variance, $P_{\mathrm{N}} / C_{\mathrm{i}}$ was $l n$ transformed; otherwise ( $\alpha$-carotene/ $\beta$-carotene), the Mann-Whitney rank sum test was used to test for differences between median values. Standard error bars shown in figures are based on untransformed data.

\section{Results}

Leaf mass area: There was no significant difference between SHB and NHB for fresh mass/dry mass ratio but these foliage types did differ in mass per area (Table 1). Both fresh and dry leaf mass area of SHB were higher than NHB.

Gas exchange: Fig. 2 shows the gas-exchange parameters of SHB and NHB of savin juniper. The NHB had significantly higher area-based $P_{\mathrm{N}}, g_{\mathrm{s}}, E, P_{\mathrm{N}} / C_{\mathrm{i}}$, and $\mathrm{WUE}_{\mathrm{i}}$, compared to the SHB (Fig. $2 A-E$ ). Nonetheless, the $C_{\mathrm{i}} / C_{\mathrm{a}}$ of SHB was higher than that in NHB (Fig. $2 F$ ). The higher $C_{\mathrm{i}} / C_{\mathrm{a}}$, together with the lower $P_{\mathrm{N}}$ in SHB (Fig. $2 A, F$ ) indicated that SHB suffered from nonstomatal limitations. Furthermore, because of the higher leaf mass area in SHB (Table 1 ), differences in $P_{\mathrm{N}}, g_{\mathrm{s}}, E$, and $P_{\mathrm{N}} / C_{\mathrm{i}}$ would be even more pronounced if expressed on a per unit mass basis.

Chl fluorescence: The $F_{v} / F_{m}$ of both SHB and NHB was lower than 0.75 , but $F_{v} / F_{m}$ was significantly lower in the SHB compared to that of NHB (Fig. 3A). These results indicate that both the SHB and NHB leaves suffered photoinhibition, but the SHB were more seriously affected.

Compared to the SHB, significantly higher values for $\Phi_{\text {PSII }}$ and ETR were observed in the NHB (Fig. 3B,C). However, NPQ in the SHB was significantly higher than that in the NHB (Fig. 3D). These results indicate that the NHB had stronger PSII photochemical activity, while the SHB were more engaged in photoprotection.

Pigment concentrations and ratios: Table 2 shows the main photosynthetic pigment concentrations and their ratios in SHB and NHB. The concentrations of Chl $a, \mathrm{Chl} b$, and Chl $(a+b)$ in the NHB were significantly higher than those measured in the SHB, however, SHB had a higher $\mathrm{Chl} a / b$ ratio. The higher $\mathrm{Chl}$ in NHB was consistent with their higher photosynthetic rate (Fig. 1A). Significantly higher total Car concentration and $\mathrm{Car} / \mathrm{Chl}$ ratio were observed in the SHB than that in the NHB.

Zeaxanthin was significantly higher in SHB than that in NHB (Table 2). In contrast, the antheraxanthin concentration of the SHB was significantly lower than that of the NHB. Lutein and total xanthophyll contents were also much higher in SHB.

No significant differences were detected in the measured $\alpha$-carotene, $\beta$-carotene, and total carotene concentrations between the two branchlet types (Table 2). However, the $\alpha$-carotene $/ \beta$-carotene ratio of SHB was significantly higher than in the NHB.

\section{Discussion}

Scale leaves have long been considered to have an advantage over needle leaves in habitats which are dry and cold (de Laubenfels 1953). Studies of juvenile and adult foliage of Juniperus occidentalis Hook. led Miller et al. (1995) to conclude that needles, because of higher photosynthetic rates and lower construction costs, should enhance establishment and early growth; whereas scale leaves, being more resource conservative, reflect a more stresstolerant strategy required by larger trees.

Previous work on savin juniper is consistent with this conclusion but also led Tanaka-Oda et al. (2010) to suggest that needle leaves are more tolerant of shade, while scale leaves are better able to avoid photoinhibition. Our data on sun-exposed branchlets holding needle and scale leaves suggest that SHB have lower photosynthetic rates (both area and mass based) putting them at more risk of photoinhibition in the first place.

Gas exchange: Tanaka-Oda et al. (2010) reported that 'needle leaves' had lower light-saturated $P_{\mathrm{N}}$ than that of 'scale leaves' on an area basis (but higher on a mass basis), and a lower water-use efficiency, which is not unlike shade leaves. In contrast, we observed that NHB had a higher $P_{\mathrm{N}}$ (both area and mass based) than SHB, and that they also had higher $E, g_{\mathrm{s}}$, and $\mathrm{WUE}_{\mathrm{i}}$. Generally, the higher the photosynthetic rate under the same saturated PAR, the higher the plant's light-use efficiency and, under strong light, the less prone it would be to light stress because there would be less energy to dissipate (Dong et al. 2001). This is typical of sun leaves, not shade leaves, suggesting that parallels between sun vs. shade and scale $v s$. needle leaves are not straightforward. Both scale- vs.

Table 1. Comparison of branchlet mass area parameters in scale-holding branchlets (SHB) and needle-holding branchlets (NHB) of Juniperus sabina L. Data are reported as mean \pm SE $(n=25)$ and asterisks indicate significant differences between SHB and NHB at $p<0.001\left({ }^{* * *}\right)$, and ns means $p>0.05$.

\begin{tabular}{llll}
\hline Branchlet type & Fresh mass/dry mass & Fresh leaf mass area $\left[\mathrm{g} \mathrm{m}^{-2}\right]$ & Dry leaf mass area $\left[\mathrm{g} \mathrm{m}^{-2}\right]$ \\
\hline Scale-holding & $2.16 \pm 0.02^{\text {ns }}$ & $567.6 \pm 7.5^{* * *}$ & $263.1 \pm 4.7^{* * *}$ \\
Needle-holding & $2.13 \pm 0.02^{\text {ns }}$ & $482.5 \pm 13.5^{* * *}$ & $226.5 \pm 6.5^{* * *}$ \\
\hline
\end{tabular}




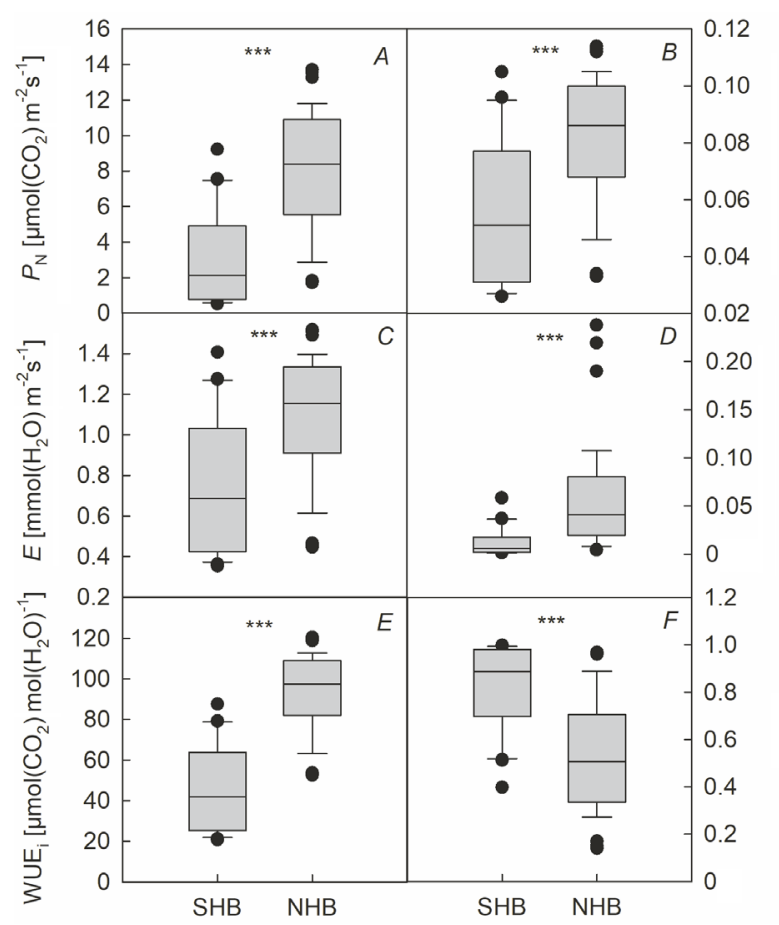

Fig. 2. Comparison of photosynthetic parameters in scale-holding branchlets (SHB) and needle-holding branchlets (NHB) of Juniperus sabina L. $C_{\mathrm{i}} / C_{\mathrm{a}}$ - ratio of intercellular to atmospheric $\mathrm{CO}_{2}$ concentration; $E$ - transpiration rate; $g_{\mathrm{s}}$ - stomatal conductance; $P_{\mathrm{N}}-$ net photosynthetic rate; $P_{\mathrm{N}} / C_{\mathrm{i}}-$ instantaneous efficiency of carboxylation; $\mathrm{WUE}_{\mathrm{i}}$ - intrinsic water-use efficiency. In boxplots, the black line indicates the median, the box boundaries represent the lower and upper quartile, the whiskers the $5^{\text {th }}$ and $95^{\text {th }}$ percentile and outliers are depicted as black dots. Error bars here indicate the standard error $(n=39)$ and asterisks indicate significant differences between SHB and NHB at $p<0.001\left({ }^{* * *}\right)$.

needle-holding branchlets of savin juniper may adapt to strong light using different strategies; in the former case by investing in photoprotective mechanisms, and in the latter case by having a high photosynthetic capacity.

The lower $g_{\text {s }}$ of SHB may reflect their appressed leaf arrangement and lower stomatal density (Zhang et al. 2017). Savin juniper has stomata only on the adaxial leaf surface, resulting in a more tortuous path for $\mathrm{CO}_{2}$ diffusion into the leaf. Despite their lower $g_{\mathrm{s}}$, the $C_{\mathrm{i}} / C_{\mathrm{a}}$ was higher in the SHB, suggesting a greater nonstomatal limitation. The much lower $P_{\mathrm{N}} / C_{\mathrm{i}}$ of $\mathrm{SHB}$ relative to $\mathrm{NHB}$ is consistent with this interpretation. A higher nonstomatal limitation may reflect a lower photosynthetic capacity, a greater post-stomatal resistance to $\mathrm{CO}_{2}$ diffusion (i.e., a lower mesophyll conductance), or both.

Chl fluorescence: The maximal dark-state efficiency of PSII $\left(\mathrm{F}_{\mathrm{v}} / \mathrm{F}_{\mathrm{m}}\right)$ of both branchlet types was lower than 0.75 , indicating some level of photoinhibition and suggesting that both SHB and NHB were exposed to excess sunlight. The SHB, however, had lower $F_{v} / F_{m}$ than that of the NHB consistent with a greater photochemical limitation, as also shown by higher NPQ, lower ETR, lower $\Phi_{\text {PSII }}$ and lower $P_{\mathrm{N}}$ in the SHB. NPQ of excitation energy is an important

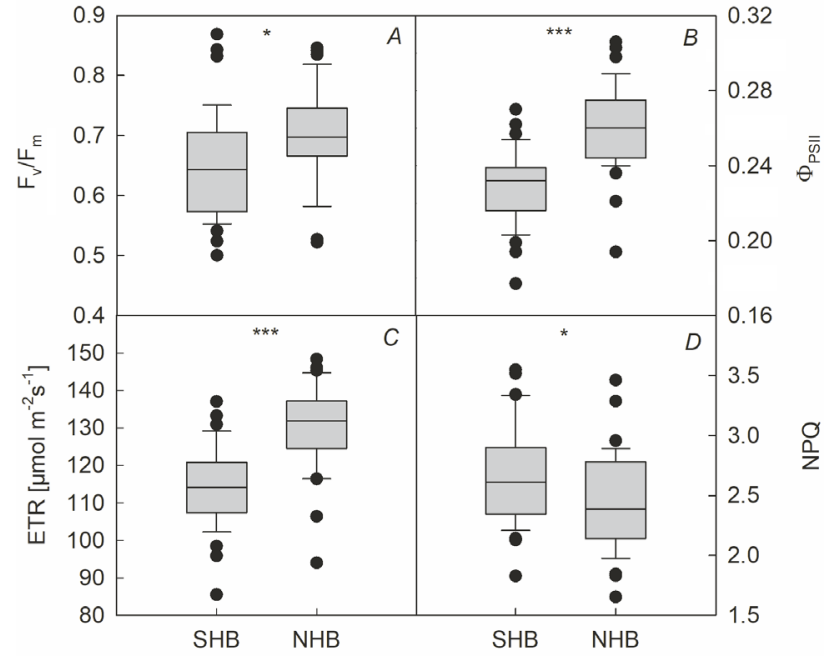

Fig. 3. Comparison of chlorophyll fluorescence parameters in scale-holding branchlets (SHB) and needle-holding branchlets (NHB) of Juniperus sabina L. ETR - electron transport rate; $\mathrm{F}_{\mathrm{v}} / \mathrm{F}_{\mathrm{m}}$ - PSII maximal efficiency in the dark state; NPQ nonphotochemical quenching; $\Phi_{\mathrm{PSII}}-\mathrm{PSII}$ operational efficiency. In boxplots, the black line indicates the median, the box boundaries represent the lower and upper quartile, the whiskers the $5^{\text {th }}$ and $95^{\text {th }}$ percentile and outliers are depicted as black dots. Error bars here indicate the standard error $(n=39)$ and asterisks indicate significant differences between SHB and NHB at $p<0.05\left(^{*}\right)$ or $p<0.001\left(^{* * *}\right)$.

Table 2. Comparison of chlorophyll and carotenoid concentrations in scale-holding branchlets (SHB) and needle-holding branchlets (NHB) of Juniperus sabina L. Chl - chlorophyll; Chl $a$ - chlorophyll $a$; Chl $b-$ chlorophyll $b$. All concentrations are expressed per unit of fresh mass. Data are reported as mean \pm SE $(n=39)$ (ns $-p>0.05,{ }^{*}-p<0.05,{ }^{* *}-p<0.01,{ }^{* * *}-p<0.001$ ).

\begin{tabular}{lll}
\hline & Scale-holding & Needle-holding \\
\hline $\mathrm{Chl} a\left[\mathrm{mg} \mathrm{g}^{-1}\right]$ & $0.88 \pm 0.02^{* * *}$ & $1.15 \pm 0.02^{* * *}$ \\
$\mathrm{Chl} b\left[\mathrm{mg} \mathrm{g}^{-1}\right]$ & $0.25 \pm 0.01^{* * *}$ & $0.34 \pm 0.01^{* * *}$ \\
$\mathrm{Chl} a / b$ & $3.55 \pm 0.03^{* *}$ & $3.42 \pm 0.03^{* *}$ \\
$\mathrm{Chl}(a+b)\left[\mathrm{mg} \mathrm{g}^{-1}\right]$ & $1.13 \pm 0.02^{* * *}$ & $1.49 \pm 0.02^{* * *}$ \\
Carotenoids $\left[\mathrm{mg} \mathrm{g}^{-1}\right]$ & $0.34 \pm 0.01^{*}$ & $0.32 \pm 0.01^{*}$ \\
Carotenoids $/ \mathrm{Chl}^{*}$ & $0.302 \pm 0.002^{* * *}$ & $0.214 \pm 0.002^{* * *}$ \\
Zeaxanthin $\left[\mu \mathrm{g} \mathrm{g}^{-1}\right]$ & $3.34 \pm 0.03^{* * *}$ & $2.65 \pm 0.03^{* * *}$ \\
Antheraxanthin $\left[\mu \mathrm{g} \mathrm{g}^{-1}\right]$ & $2.18 \pm 0.03^{* * *}$ & $2.88 \pm 0.03^{* * *}$ \\
Lutein $\left[\mu \mathrm{g} \mathrm{g}^{-1}\right]$ & $56.8 \pm 0.4^{* * *}$ & $35.8 \pm 0.3^{* * *}$ \\
Xanthophylls $\left[\mu \mathrm{g} \mathrm{g}^{-1}\right]$ & $67.8 \pm 0.5^{* * *}$ & $49.0 \pm 0.5^{* * *}$ \\
$\alpha$-carotene $\left[\mu \mathrm{g} \mathrm{g}^{-1}\right]$ & $55.0 \pm 3.5^{\text {ns }}$ & $49.1 \pm 3.0^{\text {ns }}$ \\
$\beta$-carotene $\left[\mu \mathrm{g} \mathrm{g}^{-1}\right]$ & $197.0 \pm 7.1^{\text {ns }}$ & $212.5 \pm 6.6^{\mathrm{ns}}$ \\
$\alpha$-carotene $/ \beta$-carotene & $0.27 \pm 0.01^{* *}$ & $0.23 \pm 0.01^{* *}$ \\
Carotenes $\left[\mu \mathrm{g} \mathrm{g}^{-1}\right]$ & $252.0 \pm 10.3^{\text {ns }}$ & $261.6 \pm 9.2^{\text {ns }}$ \\
\hline
\end{tabular}

photoprotective mechanism in plants, and is an efficient way of avoiding PSII photodamage and acclimating to high sunlight (Gilmore 1997, Krause and Jahns 2004).

Tanaka-Oda et al. (2010) did not measure fluorescence in savin juniper under field conditions, as in the present study, but did perform a laboratory test where they 
monitored $\mathrm{F}_{\mathrm{v}} / \mathrm{F}_{\mathrm{m}}$ to assay the susceptibility of dark-adapted 'scale leaves' and 'needle leaves', cut from a sun-exposed canopy position, after a $2-\mathrm{h}$ exposure to strong light $\left[2,000 \mu \mathrm{mol}\right.$ (photon) $\left.\mathrm{m}^{-2} \mathrm{~s}^{-1}\right]$. In their experiment, both leaf types were strongly photoinhibited, but $\mathrm{F}_{\mathrm{v}} / \mathrm{F}_{\mathrm{m}}$ was more markedly reduced in needle leaves $(\sim 0.46$, as compared to $\sim 0.66$ in the scale leaves). These contrasting results may reflect the contrasting situations (i.e., operational field conditions vs. an abruptly imposed high light). Scale leaves are presumably at an advantage over needle leaves when energy dissipation by photochemistry cannot keep pace with light absorption, but under less stressful conditions, the higher photosynthetic capacity of needle leaves is enough to avoid serious overreduction.

In a comparison of several tropical cloud forest species, Quevedo-Rojas et al. (2018) found that some species were able to acclimate to increased light through enhanced NPQ, while others did so by increasing $\Phi_{\text {PSII }}$ and ETR without an increase in NPQ. Interestingly, as shown here, savin juniper simultaneously has higher NPQ in SHB and higher $\Phi_{\text {PSII }}$ and ETR in NHB. Heterophylly may therefore allow savin juniper to combine these two different strategies. Higher NPQ suggests a more strongly developed capacity for the thermal dissipation of excess energy in SHB by way of the appropriate pigments.

Pigments: Chl concentration is an important factor impacting the rate of photosynthesis and the required photoprotection (Ma et al. 2015). Consistent with their higher photosynthetic rate and greater need for light capture (Murchie and Horton 1997), the NHB had higher concentrations of Chl $a, \mathrm{Chl} b$, and $\mathrm{Chl}(a+b)$ than that of the SHB. It is possible that scale leaves had a lower Chl content because of more irradiance-induced damage to pigments than in needle leaves, but this was not explored directly. In fact, their better photoprotection would help prevent such a damage. Although the Chl $a / b$ of SHB was significantly higher than that in the NHB, it was only marginally so (3.55 vs. 3.42), consistent with them being acclimated to the same light conditions. Typical Chl $a / b$ ratios for sun and shade leaves are 3.5-4.9 and 1.6-2.2, respectively (Porra 2002). Therefore, in terms of these ratios, SHB are slightly more like sun leaves than NHB are, but NHB clearly have the potential to adjust to strong sunlight.

Car facilitate the absorption and transmission of light energy, and protect the photosynthetic apparatus if the absorption of radiant energy exceeds photosynthetic capacity (Demmig-Adams and Adams 1996, Niyogi et al. 1997, Ke 2003). SHB had the higher total Car concentration and $\mathrm{Car} / \mathrm{Chl}$ ratio. Although SHB have a reduced total Chl, commensurate with lower $P_{\mathrm{N}}$, their enhanced total Car concentration and $\mathrm{Car} / \mathrm{Chl}$ ratio should provide better photoprotection. Most particularly, total xanthophylls were almost $40 \%$ more abundant in SHB.

Xanthophylls (including those in the xanthophyll cycle and lutein) can assist in protection against light stress and are the main mechanism preventing photoinhibition in plants (Zakar et al. 2017), they are crucial as physical quenchers that promote thermal dissipation or NPQ, an efficient energy-dissipation mechanism in plants (DemmigAdams and Adams 1996). The xanthophyll cycle pool changes intensely and variably (Björkman and DemmigAdams 1995, Dong et al. 2001). Together, genetic predisposition and the light environment normally determine the size and composition of the xanthophyll cycle pool (Thayer and Björkman 1990). We found significant differences in zeaxanthin and antheraxanthin concentrations in heteromorphic leaves of savin juniper, illustrating that leaf form also influences the xanthophyll cycle pool.

Higher xanthophyll cycle deepoxidation activity results in higher zeaxanthin, which helps prevent damage to the photosynthetic apparatus (Gruszecki et al. 2006). NPQ is linearly and closely related to the zeaxanthin content (Demmig-Adams et al. 1996). The higher zeaxanthin and NPQ of SHB indicate a higher capacity for photoprotection. Lutein also helps dissipate excess light energy and protect plants from photoxidative damage (Niyogi et al. 1997). Lutein content was much higher in SHB than that in NHB. Future work should further explore the function of lutein (or the lutein cycle) in photoprotection of savin juniper.

Lutein is the hydroxylated derivative of $\alpha$-carotene (Niyogi et al. 1997). The higher $\alpha$-carotene concentration and $\alpha$-carotene/ $\beta$-carotene ratio in the SHB are therefore consistent with their higher lutein concentration. Zeaxanthin is a derivative of $\beta$-carotene (Niyogi et al. 1997); however, there were no differences in the $\beta$-carotene concentration between the two branchlet types. We speculate that the extremely high concentration of $\beta$-carotene relative to the other carotenoids (i.e., about 66 and 4 times more than zeaxanthin and $\alpha$-carotene, respectively) may be the reason why the trends in $\beta$-carotene and zeaxanthin are not in conformity. The higher zeaxanthin concentration of the SHB may be more immediately determined by xanthophyll cycle deepoxidation activity. We were unable to directly compare violaxanthin contents between SHB and NHB because this pigment was not resolved from neoxanthin during chromatography, but the combined concentration of these two pigments was $~ 35 \%$ higher in NHB (not shown). As neoxanthin concentrations are reported to be relatively stable across leaf types (Esteban et al. 2015, Dörken and Lepetit 2018), this suggests that violaxanthin deepoxidation was more prevalent in scale leaves.

These results indicate greater engagement of the xanthophyll thermal dissipation mechanism (including xanthophyll cycle and lutein) in SHB than that in NHB. Furthermore, the higher $\alpha$-carotene concentration and $\alpha$-carotene $/ \beta$-carotene ratio suggest that $\alpha$-carotene might also contribute to greater protection against excess light energy in the SHB. Overall, the photoprotective carotenoids, namely zeaxanthin, lutein, and $\alpha$-carotene, are the principal thermal dissipation pigments increasing the relative capacity to consume excess light energy in the SHB.

Conclusion: The lower photosynthetic rate of SHB relative to NHB, in the same full sun light environment, provides SHB with less opportunity than NHB for photochemical quenching. In compensation, photoprotective mechanisms are better developed in SHB than they are in NHB, enabling SHB to dissipate more excess 
light energy as heat in the xanthophyll cycle or through lutein. Overall, as indicated by a lower $\mathrm{F}_{\mathrm{v}} / \mathrm{F}_{\mathrm{m}}$, the SHB were slightly more photoinhibited than NHB, but not greatly so, and, based on the work of Tanaka-Oda et al. (2010), would likely far better under more stressful conditions. It is not otherwise clear from the present study if or what the compensating benefit might be. Water-use efficiency and carboxylation efficiency were both higher in NHB. SHB had lower transpiration rates, so, despite a lower $\mathrm{WUE}_{\mathrm{i}}$, should be better able to conserve water for purposes of storage and survival in the desert environment. Heterophylly could therefore be beneficial to savin juniper by providing functional flexibility over the use of environmental resources (such as light and water) as conditions vary in time and space.

\section{References}

Björkman O., Demmig-Adams B.: Regulation of photosynthetic light energy capture, conversion, and dissipation in leaves of higher plants. - In: Schulze E.D., Caldwell M.M. (ed.): Ecophysiology of Photosynthesis. Pp. 17-47. Springer, Berlin 1995.

Cao H., Zhang J., Xu J. et al:: Comprehending crystalline $\beta$-carotene accumulation by comparing engineered cell models and the natural carotenoid-rich system of citrus. J. Exp. Bot. 63: 4403-4417, 2012.

Cazzaniga S., Bressan M., Carbonera D. et al.: Differential roles of carotenes and xanthophylls in photosystem I photoprotection.Biochemistry-US 55: 3636-3649, 2016.

de Laubenfels D.J.: The external morphology of coniferous leaves. - Phytomorphology 3: 1-20, 1953.

Demmig-Adams B., Adams III W.W., Barker D.H. et al.: Using chlorophyll fluorescence to assess the fraction of absorbed light allocated to thermal dissipation of excess excitation. Physiol. Plantarum 98: 253-264, 1996.

Demmig-Adams B., Adams III W.W.: The role of xanthophyll cycle carotenoids in the protection of photosynthesis. - Trends Plant Sci. 1: 21-26, 1996.

Deschamp P.A., Cooke T.J.: Leaf dimorphism in the aquatic angiosperm Callitriche heterophylla. - Am. J. Bot. 72: 1377-1387, 1985.

Dong G., Chen Y., Li G. et al.: [Xanthophyll cycle and nonradiative energy dissipation in sun and shade plants.] J. Wuhan Bot. Res. 19: 128-134, 2001. [In Chinese]

Dörken V. M., Lepetit B.: Morpho-anatomical and physiological differences between sun and shade leaves in Abies alba Mill. (Pinaceae, Coniferales): a combined approach. - Plant Cell Environ. 41: 1683-1697, 2018.

Esteban R., Barrutia O., Artetxe U. et al.: Internal and external factors affecting photosynthetic pigment composition in plants: a meta-analytical approach. - New Phytol. 206: 268-280, 2015.

Gilmore A.M.: Mechanistic aspects of xanthophyll cycledependent photoprotection in higher plant chloroplasts and leaves. - Physiol. Plantarum 99: 197-209, 1997.

Gruszecki W.I., Grudzinski W., Gospodarek M. et al.: Xanthophyll-induced aggregation of LHCII as a switch between light-harvesting and energy dissipation systems. - BBABioenergetics 1757: 1504-1511, 2006.

Hao J., Yue N., Zheng C.: Analysis of changes in anatomical characteristics and physiologic features of heteromorphic leaves in a desert tree, Populus euphratica. - Acta Physiol. Plant. 39: 160, 2017.
He W., Zhang X., Dong M.: Gas exchange, leaf structure, and hydraulic features in relation to sex, shoot form, and leaf form in an evergreen shrub Sabina vulgaris in the semi-arid $\mathrm{Mu}$ Us Sandland in China. - Photosynthetica 41: 105-109, 2003.

He W., Zhang X.: [Ecological significance of change of leaf form in Sabina vulgaris.] - Acta Bot. Yunnan. 23: 433-438, 2001. [In Chinese]

He W., Zhang X.: Responses of an evergreen shrub Sabina vulgaris to soil water and nutrient shortages in the semi-arid Mu Us Sandland in China. - J. Arid Environ. 53: 307-316, 2003.

Jahns P., Holzwarth A.R.: The role of the xanthophyll cycle and of lutein in photoprotection of photosystem II. - BBABioenergetics 1817: 182-193, 2012.

Kane M.E., Albert L.S.: Environmental and growth regulator effects on heterophylly and growth of Proserpinaca intermedia (Haloragaceae). - Aquat. Bot. 13: 73-85, 1982.

Kang M.Y., Dong S., Huang X. et al.: Ecological regionalization of suitable trees, shrubs and herbages for vegetation restoration in the farming-pastoral zone of northern China. - Acta Bot. Sin. 45: 1157-1165, 2003.

$\mathrm{Ke}$ B.: Role of carotenoids in photosynthesis. - In: Photosynthesis. Photobiochemistry and Photobiophysics. Pp. 229-250. Springer, Dordrecht 2003.

Kitao M., Lei T.T., Koike T. et al.: Temperature response and photoinhibition investigated by chlorophyll fluorescence measurements for four distinct species of dipterocarp trees. Physiol. Plantarum 109: 284-290, 2000.

Kopsell D.A., Sams C.E., Morrow R.C.: Interaction of light quality and fertility on biomass, shoot pigmentation and xanthophyll cycle flux in Chinese kale. - J. Sci. Food Agr. 97: 911-917, 2017.

Krause G.H., Jahns P.: Non-photochemical energy dissipation determined by chlorophyll fluorescence quenching: characterization and function. - In: Papageorgiou G.C., Govindjee (ed.): Chlorophyll $a$ Fluorescence. Pp. 463-495. Springer, Dordrecht 2004.

Lee D.W., Richards J.H.: Heteroblastic development in vines. In: Putz F.E., Mooney H.A. (ed.): The Biology of Vines. Pp. 205-243. Cambridge University Press, Cambridge 1991.

Lee P.C., Schmidt-Dannert C.: Metabolic engineering towards biotechnological production of carotenoids in microorganisms. - Appl. Microbiol. Biot. 60: 1-11, 2002.

Lichtenthaler H.K.: Chlorophylls and carotenoids: Pigments of photosynthetic biomembranes. - Method. Enzymol. 148: 350-382, 1987.

Liu Q., Xu J., Liu Y. et al.: A novel bud mutation that confers abnormal patterns of lycopene accumulation in sweet orange fruit (Citrus sinensis L. Osbeck). - J. Exp. Bot. 58: 4161-4171, 2007.

Ma X., Song L., Yu W. et al.: Growth, physiological, and biochemical responses of Camptotheca acuminata seedlings to different light environments. - Front. Plant Sci. 6: 321, 2015.

Miller P.M., Eddleman L.E., Miller J.M.: Juniperus occidentalis juvenile foliage: advantages and disadvantages for a stresstolerant, invasive conifer. - Can. J. Forest Res. 25: 470-479, 1995.

Mouget J.L., Tremblin G.: Suitability of the fluorescence monitoring system (FMS, Hansatech) for measurement of photosynthetic characteristics in algae. - Aquat. Bot. 74: 219-231, 2002.

Murchie E.H., Horton P.: Acclimation of photosynthesis to irradiance and spectral quality in British plant species: chlorophyll content, photosynthetic capacity and habitat preference. - Plant Cell Environ. 20: 438-448, 1997. 
Nakayama H., Sinha N.R., Kimura S.: How do plants and phytohormones accomplish heterophylly, leaf phenotypic plasticity, in response to environmental cues. - Front. Plant Sci. 8: 1717, 2017.

Nicotra A.B., Leigh A., Boyce C.K. et al.: The evolution and functional significance of leaf shape in the angiosperms. Funct. Plant Biol. 38: 535-552, 2011.

Niyogi K.K., Björkman O., Grossman A.R.: The roles of specific xanthophylls in photoprotection. - P. Natl. Acad. Sci. USA 94: 14162-14167, 1997

Paine J.A., Shipton C.A., Chaggar S. et al.: Improving the nutritional value of Golden Rice through increased provitamin A content. - Nat. Biotechnol. 23: 482-487, 2005.

Palacio-López K., Beckage B., Scheiner S., Molofsky J.: The ubiquity of phenotypic plasticity in plants: a synthesis. Ecol. Evol. 5: 3389-3400, 2015.

Pastenes C., Pimentel P., Lillo J.: Leaf movements and photoinhibition in relation to water stress in field-grown beans. J. Exp. Bot. 56: 425-433, 2005

Porra R.J.: The chequered history of the development and use of simultaneous equations for the accurate determination of chlorophylls $a$ and $b$. - Photosynth. Res. 73: 149-156, 2002.

Quevedo-Rojas A., García-Núñez C., Jerez-Rico M. et al.: Leaf acclimation strategies to contrasting light conditions in saplings of different shade tolerance in a tropical cloud forest. Funct. Plant Biol. 45: 968-982, 2018.

Ray T.S.: Cyclic heterophylly in Syngonium (Araceae). - Am. J. Bot. 74: 16-26, 1987.

Ray T.S.: Metamorphosis in the Araceae. - Am. J. Bot. 77: 1599-1609, 1990.

Ribeiro R.V., Machado E.C., Santos M.G., Oliveira R.F.: Seasonal and diurnal changes in photosynthetic limitation of young sweet orange trees. - Environ. Exp. Bot. 66: 203-211, 2009.

Steinbauer M.J.: Oviposition preference and neonate performance of Mnesampela privata in relation to heterophylly in Eucalyptus dunnii and E. globulus. - Agr. Forest Entomol. 4: 245-253, 2002.

Tanaka-Oda A., Kenzo T., Kashimura S. et al:: Physiological and morphological differences in the heterophylly of Sabina vulgaris Ant. in the semi-arid environment of Mu Us Desert, Inner Mongolia, China. - J. Arid Environ. 74: 43-48, 2010.

Thayer S.S., Björkman O.: Leaf xanthophyll content and composition in sun and shade determined by HPLC. J. Photosynth. Res. 23: 331-343, 1990.
Ueno M., Sae-Tang P., Kusama Y. et al.: Moderate heat stress stimulates repair of photosystem II during photoinhibition in Synechocystis sp. PCC 6803. - Plant Cell Physiol. 57: 2417-2426, 2016.

Wang L., Dang H., Zhang G. et al.: [Distribution and biomass of natural Juniperus sabina community in China.] - Inner Mongolia Agric. Univ. 1: 37-45, 2014. [In Chinese]

Wang T.L., Wang G.G., Innes J.L. et al:: ClimateAP: an application for dynamic local downscaling of historical and future climate data in Asia Pacific. - Front. Agr. Sci. Eng. 4: 448-458, 2017.

Weger H.G., Silim S.N., Guy R.D.: Photosynthetic acclimation to low temperature by western red cedar seedlings. - Plant Cell Environ. 16: 711-717, 1993.

Winn A.A.: The functional significance and fitness consequences of heterophylly. - Int. J. Plant Sci. 160: S113-S121, 1999.

Xu D.: [Several problems in the research of plant light stress.] Plant Physiol. Commun. 39: 493-495, 2003. [In Chinese]

Yuan L., Wang C., Huang X. et al.: [The regulation of 24-epibrassinolide on AsA-GSH cycle and xanthophylls homeostasis in chloroplast of cucumber under $\mathrm{Ca}\left(\mathrm{NO}_{3}\right)_{2}$ stress.] - Acta Hortic. Sin. 44: 881-890, 2017. [In Chinese]

Zakar T., Herman E., Vajravel S. et al.: Lipid and carotenoid cooperation-driven adaptation to light and temperature stress in Synechocystis sp. PCC6803. - BBA-Bioenergetics 1858: 337-350, 2017.

Zhang J.L., Chen H.P., Li Y.L. et al.: [Comparison of water characteristics in the heterophylly of Sabina vulgaris.] J. Arid Land Res. Environ. 32: 154-159, 2018. [In Chinese]

Zhang J.L., Cheng D., Li Y.L. et al.: [Effect of light and water stress on photochemical efficiency and pigment composition of Sabina vulgaris seedlings.] - Chin. Bull. Bot. 3: 278-289, 2017. [In Chinese]

Zhang J.L., Li Y.L., Pang M.L. et al.: [Comparison of drought resistance of anatomical structure in the heterophylly mechanism of Sabina vulgaris.] - Acta Bot. Boreal.-Occident. Sin. 37: 1756-1763, 2017. [In Chinese]

Zhang S., Li Q., Ma K., Chen L.: Temperature-dependent gas exchange and stomatal/non-stomatal limitation to $\mathrm{CO}_{2}$ assimilation of Quercus liaotungensis under midday high irradiance. - Photosynthetica 39: 383-388, 2001.

Zhang W., Xu A., Zhang R. et al.: [Review of soil classification and revision of China soil classification system.] - Sci. Agr. Sin. 47: 3214-3230, 2014. [In Chinese]

(C) The authors. This is an open access article distributed under the terms of the Creative Commons BY-NC-ND Licence. 